\title{
How Tourist Destinations Could Be Stereotyped and Misplaced by Structural Forces? - A Case of Penghu Archipelago, Taiwan
}

\author{
Han-Chun $\mathrm{Tu}^{1}$, Shew-Jiuan $\mathrm{Su}^{2}$ \\ ${ }^{1}$ Adjunct Assistant Professor, Department of Applied History, National Chiayi University, Taiwan \\ ${ }^{2}$ Professor, Department of Geography, National Taiwan Normal University, Taiwan
}

\begin{abstract}
Tourist destination image is important for strategic marketing and tourist choice. While many studies focus on images and their influencing factors, images are wrongly considered only for sale, compromising local authenticity and local life. With a critical review of development plans and the results of a questionnaire survey, this paper argues that images often stereotype and misplace tourist destination, in particularly for images brought about by structural forces. Islands are lands surrounded by ocean and often taken as full of marine and coastal resources and sceneries. In Penghu archipelago, marine environment is important for local livelihood and tourist destination. However, with the case of Erkan, we realize that, along with the evidence from interviews and surveys, most Erkan tourists do not come for its marine or natural resources. Erkan, as a fishing village, was turned into a tourism destination for tis vernacular architecture and folklore products irrelevant to its marine environment. With structural endeavours and official makeover of places, places are stereotyped and often become out of place.
\end{abstract}

\section{Introduction}

Penghu archipelago is famous for its marine resources. Fishing life are technically, culturally and economically inherent to these islets and their people. Tidal flats, fishing weirs, and seaweed harvesting are of intensive techniques, culture and local knowledge. But with structurally imposed renovation plans that are foreign to fishing villages, some places of the Archipelago are misplaced due to the loss of authentic beauty and local identity.

Tourist studies often emphasize demand sides. When the supply side is emphasized, the authentic characteristics of tourist destinations may not be considered thoroughly. For attracting tourists, local identity and local beauties often would have to be altered or compromised either through promotion or marketing that appeals or follows tourist interest. In this study, we argue for the significance of maintaining the authenticity and local identity of places by analyzing and criticizing the influential structural forces in changing the images of a tourist destination. Tourism developed along the line of natural resources is considered authentic as it consumes the scenes and landscapes that grow out of the local cultural and natural environments. When the local image is altered due to tourist and business needs, a different and stereotyped image thus can be developed. That may displace local identity.

Crompton suggested two types of destination images, person-dominated and the other destination determined [1]. His suggestion signifies personal experience/perception in image making. Phelps 
pointed out primary and secondary images, with a difference of visit experience. The comparison of such images can only be made after visit experience [2]. The idea of organic image of tourist destination is one developed through individual assimilation of information of tourist destination [3-4]. Gunn's idea of organic image and induced image point to the difference that market promoters can make. All above mentioned classification of images are studied with marketing in mind and with tourism as an economic practice. These are parallel to what Baloglu and McCleary pointed out in the turn of the century: "research of the past two decades has demonstrated that image is a valuable concept in understanding the destination selection process" (p. 868) [5]. Even studies focused on destination image formation, much is done on how image is formed by personal and stimulus factors, but not how structural factors influence image making. In some recent synthetic studies (e.g., Gallarza et al. 2002; Beerli and Martín 2004) of factors determining images, mainly cognitive, affective and other personal and stimulate factors are mostly considered. Structural elements embedded in the tourist destination are ignored.

Image management for tourist destination is important, but understanding destination images only through the personal and stimulus factors, and through cognitive and affective process are not allinclusive. This paper will use Erkan as a case study to investigate how structural forces are done to set, alter or stereotype place image. Such study is important because place images are not only for sale, but also subjects of places and mentalities of their people, in and of which true life with livelihood and socio-environmental ecology exist. Images do not exist solely for tourist sake, neither for a price.

With reviewing of destination image, this paper argues for extending image study into a place's historical accumulation. We explains the influential historical development of vernacular architectural renovation of Erkan, where stereotyped image of vernacular architectural facade and certain local products is set. Its abundant natural resources is thus forgotten. The image stereotyping in turn makes the nature and marine related landscape and resources of Erkan vanished in the eyes of tourists.

\section{Methods and methodology}

\subsection{Methods}

This study is based on a structuration framework to examine how structural elements and individual behaviors interplay to set certain stereotype of Erkan further. The methods for this study are two parts. First, we review the historical development for the vernacular architectural of Erkan to get insight for the origin of its image stereotyping. To this end, we analyze government policies of settlement renovation of a deteriorating fishing village where population loss was critical. To make the population loss issue more serious is that more than 90 percent of Erkan villagers was made up of the clan of Chen. Thus the collapse of Erkan means detrimental devastation of the clan in Chinese culture. Secondly, we design and conduct a questionnaire survey to gain knowledge about the tourist experience of Erkan. The survey results supplement that previous structural policies in making Erkan image is indeed significant and stereotyping, and they narrow tourists experience of Erkan.

An analysis of governmental renovation plans and forces exercised in the local area are done to understand how the stereotyped image of Erkan is achieved. With the survey, we investigate how tourists perceive Erkan, and we provide results helpful to argue for the stereotyping of Erkan image. This study first analyzes the planning, design and development endeavors of the central and local governments in enhancing vernacular and folklore landscape to slow down the death of a place. That in turn reinforce a stereotyping of Erkan. A qualitative interviews of the local people then follow.

The questionnaire survey was conducted in June 2014. It is divided into three parts, the first about the demographic data of the interviewed tourists, the second about tourist behaviors, and the third about tourist experience of Erkan and their willingness to visit again. For a good sampling, we conducted the survey during both weekdays and weekends, for both group and individual tourists, in both morning and afternoon, and both in and around the village. A total of 402 questionnaires are returned effective. Based on the estimation of National Tourism Bureau of an annual tourist number of 220 to 250 thousand for Erkan, the confidence level is $95 \%$ and confidence interval $\pm 5 \%$. 


\subsection{Structuration Concept and Its Application}

Structuration theory of Giddens is inspiring for framing this paper. On the one hand, structure refers to rules and resources, and the properties of structure bind the time-space of social systems. Resources can be classified into two types, allocative and authoritative resources. Allocative resource refers to abilities to command over material objects, and authoritative resource commands over people or actors. They are critical for understanding how Erkan was shaped by government plans to turn into a village of vernacular architecture and folklore.

Agency exists in the world of structure. Social practice is ordered across space and time, and the reflexivity of human agents as the monitored character is one of the important constitutions of social practice. The relationship between structures and agents is a duality, but not dualism. Structural properties in social system are medium and result of agents as well [6]. To understand how the misplaced marine identity of Erkan has been sustained by tourists, a questionnaire survey result is analyzed and interpreted. With structuration, not only the structural renovation programs for Erkan were critical, but the tourists' choices also contributed to stereotyping Erkan image.

\subsection{Islandness}

The idea of islandness is a complex expression of particular identity, and the perception of island as self, and mainland as other thus is strong. Island identification is deeply related to marine environments, such as coast, water, edge, and periphery. Isolation and the lack of access is another identification. As islandness may refer to specific landscapes worthy of protection [7], its application to Penghu archipelago relates much to marine environments. As important is that the marine identity of Erkan village was not as strong as many fishing villages of the archipelago, due to its site of facing internal water and lack of qualification to compete among fishing villages. Since the renovation plans, the use of marine environment for the livelihood and daily life is feeble and even forgotten.

By the end of the 1980's, Erkan witnessed villagers migrating to mainland Taiwan for economic security. Economic scarcity and lack of employment opportunity, along with declining marine environment, Erkan settlement was about to disintegrate. The fact that Erkan village was a clan settlement made population loss a particularly serious threat. The central government plans for settlement renovation were partly out of such crisis and in time, although there was a synchronizing national fashion for community cultural and vernacular architectural conservation. The renovation plans made Erkan a village foreign to fishing.

\subsection{Stereotyping Tourist Destinations}

Destination image is important in marketing and tourist decision making, but even more important is how the image has come about. As determinants for image are often divided to stimulus factors and tourists' personal characteristics [5], structural forces are often neglected. Following Gunn's image research, Fakeye suggested that tourist destination image is formed by three processes, including the organic, induced and complex image. The third image is one that is further developed as complex image when tourists actually visit and contact destinations [8]. Gallarza et al. (2002) reviewed previous researches focusing on destination image and in particular they sorted Mazanec's structuring of image format that includes objects, subjects and attributes.

The object dimension refers to destination, the subject dimension through respondent's interviews, and residents' receptiveness and landscape and surroundings are attributes analyzed. Hence, the nature of the image is multiple as gestalt [9]. A breakthrough though, but they still do not solve the problem and difference between the tourist images (including all three images just mentioned) and the local living identity, which we label as the authentic image or identity, or the local authenticity. Stereotyping is what we use in this paper to trace and argue how the structural forces and the images promoted through different phases and levels of tourism development. 
Moufakkir's study of stereotypes mainly referred to people and inter-personal relations. We revised his perception and stereotypes as the foundation of travel propensity (Figure 1), and argue that stereotypes contribute to the propensity of travel, which will influence what the tourists would choose to see at destinations [10].

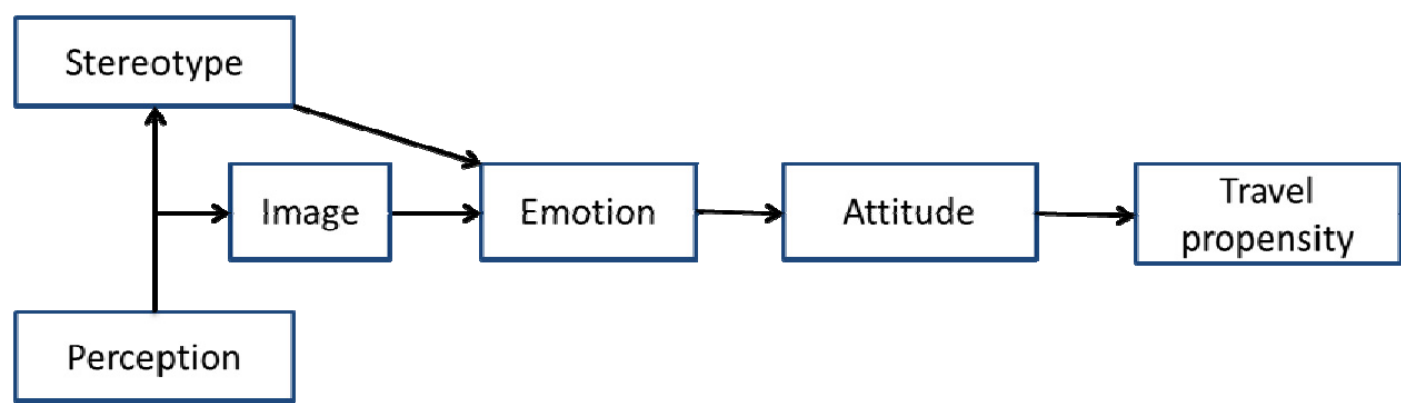

Figure 1. Stereotypes Contributing to Travel Propensity (source: revised from Moufakkir [10])

\section{Structural Plans for a Vernacular Architectural Destination}

Understanding the geography and economic life of Erkan, one will gain insights about its once vanishing fishery. Situated at east coast of Siyu Township, this village is surrounded by high lands. Erkan was a clan settlement with only one single family name, which formed an obvious blood, marital, and tight inter-personal relations. The Chen patriarchal clan lived partly on fishery and partly on agriculture in early days. That combination of economic life was different from other neighboring villages where fishing dominated. With population out-migration, the village degenerated, and the local economy and cultural landscape changed enormously [11]. At the turning point of decline, the initiatives from central government for settlement renovation came and injected it with vitality.

\subsection{The Taming of Erkan Making Vernacular Architectural Image of Erkan}

The tourism of Penghu archipelago began in the 1970s, as a rarely visited national tourist destination. With deregulation and promotion for tourism, the archipelago witnessed its first summit of tourism during 1989-1991. Tourists increased greatly, but economic benefit mostly concentrated in the city of Magong. To capitalize its natural resources for tourism, Taiwan government established the Penghu National Scenic Area Administration in 1991. Such endeavor was motivated by increasing local fishing predicaments [12].

Both Penghu County Government and the Council of Cultural Affairs (of Executive Yuan) were critical institutions to create a cultural Erkan image for tourism midst declining fishing village milieu. Erkan's authentic marine environment is tamed into image of vernacular architecture.

Degenerating Erkan seized the opportunity of rebirth. Its rebirth can be traced back to 1985 when the county government commissioned Hankwan Architect firm to evaluate traditional villages to be developed as "folklore village". Erkan Village was enlisted and selected as the most suitable village to become folklore village due to more than 30 vernacular houses were still intact. Its management was criticized for emphasizing only spatial display and neglecting local life experience and living practice. That is, the folk village emphasized mainly the façade of vernacular architecture, but ignored livelihood techniques, social relations, cultural practices, and man-nature relations. The ignorance of dynamic human relation to its nature was the most criticized [12]. 
In the early 1990s, the county designated tourism as a strategic plan for economic reason. Such deed showed the degradation of fishing and declining local income, and new economic directions needed to be planned and set in place. Without careful reasoning, Erkan tourism was focused mainly on falsely fabricated vernacular architecture. To promote Erkan conservation and to integrate scenic spots, the county government drew up an urban planning "the traditional specific area plan of Erkan", and the plan was formally announced to put into practice in 2001 [12]. This urban policy was approved by the Urban Planning Committee of the central government as the first vernacular settlement area in 2001.

To promote cultural facility and tourism resources in 2003, the county government appropriated a project of vernacular architectures from the Council of Cultural Affairs. For conservation, the county government strove for off-shore island development fund amounted to tens of thousands dollars to repair a single traditional house. With the county government's endeavors to sponsor seafood festivals all over the archipelago in 2008, Erkan was never a seafood place, as it was THE vernacular architecture site. Erkan was for activities concerning traditional building, folk music, praising songs, incense stick painting [12]. In 2003, the county government assisted the Erkan Association to propose a project of "new hometown construction plan". The Association was successfully subsidized for folk music culture heritage learning activities [12].

The management plan of the Council of Cultural Affairs in 1989 took the form of "settlement conservation" for Erkan. Hence various vernacular architectures in Erkan were renovated [12]. The Council commissioned some university architecture departments to study plan for Erkan village conservation in 1992. The Council of Cultural Affairs again promoted "Getting close to folks, native place and culture" in 1994 in a national literature and art festival. Erkan was promoted much as a historical cultural site with abundant local literature under the activity. The ultimate goal of the Council was to implement "comprehensive community making". Further, the Chairman of the Council participated in Erkan activity to highlight the significance of settlement conservation [12-14].

Both the county government and the Council worked in accordance to open up cultural and traditional resources of Erkan. It is worth noting that these institution mostly change the authentic image of marine Erkan of long time. The organic image and the induced image of Erkan (as a traditional historic heritage) are constructed even more and strongly by not only the official institutes, but also the tourism marketers afterwards. It is fair to say that the traditional and vernacular architecture of Erkan is promoted by the central and county governments, and later by marketers and news media. Such organic and induced images of Erkan distorts the local authenticity.

\subsection{The Agency of the Erkan Association}

After when the top-down conservation plans were installed in Erkan, the villagers actively took part in cultural activities. They organized an association, entitled "Settlement Conservation Association for Erkan Village" in 1994. The Association worked in coordination with central policies for essentially every plans, such as architecture renovation, the Chen family ancestral hall $[12,14]$.

The Association carried out projects in so many ways and chances, so that the Chen clan become so proud of every concrete projects. Particularly, Erkan traditional museum was the first of the nation at community level in 2001. The ancestral hall of Chen patriarchal clan was constructed in 2003 [12, 14]. In 2007, the Association assisted the central and local governments to hold the activity of "Arts in the Community" for traditional performing arts. It deserves mentioning that the Council directed and supported the activity and the county government acted as liaison in promotion [12].

The tourism of Erkan is deeply affected by central and local governments and the Association. The governments and association are not in opposite positions on structure-agency spectrum. They form a feedback loop and mechanisms to lead the village into tourism. Taiwan's comprehensive community building plans apparently pass resources from central government to local institutes, and local places thus become the spindle of its cultural policy. Culture practice begin to change from the abstract to concrete practice of folklore, architecture and livelihood activities and performance [15]. 


\section{Interview and Survey Results of Tourists}

As this study utilizes tourist experience of Erkan to examine tourist image, this section will show such images with questionnaire results. In addition to a summary statistics, four phenomena out of the survey results worth noting: (1) the tendency of choosing architectural neauty and local products, (2) the age difference of the preferred landscape images, (3) the gender differenece of preferred landscapes, and (4) the effect of being first time visitors to Erkan.

The summary statistics (table 1) convey some important message of tourists behaviors. In terms of visitors age, Erkan seems to be chosen by younger people, in particular people under the age of 40. It is not as simmilar to general findings in tourist destinations of Taiwan. First time visitors occupy more than $60 \%$ and more than $90 \%$ of visitors willing to visit again. The means of transportation is mainly motorbikes, cars and tour bus. Given the hot and humid weather, it means that people who visit with motocycles are either adventourous or people with less budget to spend. Their tourist behaviours are thus full of implication. Given the fact that motorbikes and cars are mobile and the tourist mobility to visit various points of the village is high.

Table 1. Summary Statistics for Tourist Survey

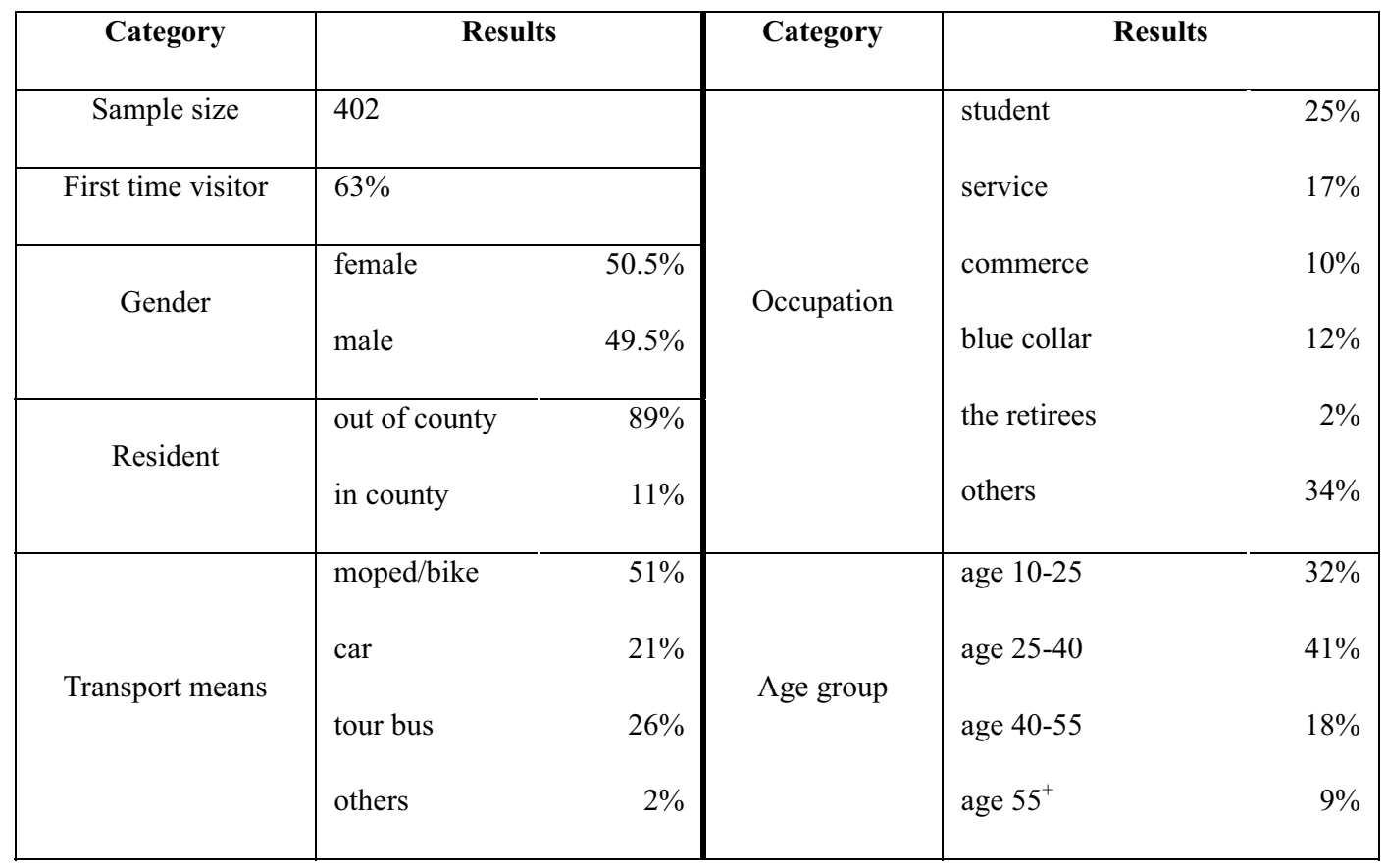

Among the five clusters of scenes and landscapes (vernacular architecture and space, folklore exhibits, religious buildings, natural and ecological landscapes, and local products), the most preferred and visited is local products (mainly confections) and the second is vernacular architecture and space. With a high percentage of willing to visit again, it seems to imply that tourists are satisfied with what thye visited in village center where vernacular architectures and local products are available. The beauty of the village related to the nautre, such as fishing weirs, basalt rocks, water resourviors, and prairie, are littlely preferred and visited. To argue that such resutls are due to the strucutral formulation of a vernacular village seems appropriate.

In ANOVA results, age plays a determining role for particular sites. Among the 45 tourist attraction sites, ten sites are statistically significant related to age. People over age 40 preferred tradition folklore and herbal medicine sites. Two sites are statistically significantly visited by younger generation, the columnar basal rocks and an ecological pond with exhibit of ox sculptures. As the 
rocks are iconic, its easy access makes tourists with cars and mortobikes chose to visit. This matches the youth's transportation means. It does not necessarily, however, mean that the young generation are with great interest for the natural beauty of basal rocks.

Gender effect is shown in ANOVA analysis. Female visitors preferred pumpkin cake, while male visitors preferred a few vernacular architecture and exhibit halls. The only site of male's cocnern related directly to the nature is the aqua-farming of off shore Erkan. In terms of first time visitors, some particular behavior was observed. For example, first time visitors prefer local confections and handycrafts. It tells much about contemporary national tousist behaviors. While the love of special foods is human and natural, it is surprising that local marine products and natural landscapes are not of concern. Among seven natural sites, only two are statistically significant for the first timers. They are columnar basalt rocks and the prairie, both are easy accessed for those with motorbikes.

As analysis indicates importantce of natural landscape, most natural scens are not visited. This finding is contradictory to the marine resoruces of the archipelago. It could be a pitfall brought about by the strucural central endeavours of promoting vernacular architecture. Vernacular architectural and folklore images of Erkan dominate, making its natural and ecological landscapes ignored.

\section{Conclusion}

With a depth survey of the central and local government's vernacular renovation endeavours for Erkan village and the results of questonnaire survey, this study argues that local images of Erkan could not be understaood fully if only organic, induced and complex images are discussed. The idea of stereotyping and stereotyped images ought to be introduced, to ensure a thorough understanding of authentic image. Tourist destination's authetic images are not only images for sale, but also images of the local life and ecology. For this reason, tourism promotion and research respecting lcoal life and authentic ways of life ought to be considered seriously and promoted properly.

The ambition of conserving vernaular architecture of Erkan was respectful. Without caution and peventive measures, however, Erkan was imprisoned into a sole image of vernacular architecture and local confections. Worse is that even the food culture representing Erkan village is narrowly stereotyped into certain agricultural produces of peanuts, pumpkins and alomnd. The resources of the ocean that Erkan villagers have been proud of are missing, such as seaweeds, urchins, fishes and shells those could be easily harveted in the tidal flats just off-shore of Erkan.

The toursim industry is importnt in image making and agenda setting of places and tourist destinations. With today's diversified tourism development and varifying interests of consumers, tourists tend to make desiosion of destination by authenticity. Thus, the promotion of authentic image, which fully respect the vernacualr life and cultural-natural environments, should be emphasized. The stereotyping of destination images ought to be understood to disclose local authenticity.

\section{References}

1. L. Crompton, An Assessment of the Image of Mexico as a Vacation Destination and the Influence of Geographical Location, Journal of Travel Research 18, 4,18-23 (1979)

2. A. Phelps, Holiday Destination Image: The problem of Assessment. An example developed in Menorca, Tourism Management 7, 3, 168-180 (1986)

3. A. Gunn, Tourism Planning (Taylor and Francis, New York, 1988)

4. P. Steven, Destination Marketing Organisations (Elsevier, Oxford, 2004)

5. S. Baloglu and K. W. McCleary, A model of destination image formation, Annals of Tourism Research 26, 4, 868-897 (1999)

6. G. Anthony, The Constitution of Society: Outline of the Theory of Structuration (Polity Press, UK, 1984)

7. S. Elaine, Islandness and struggles over development: A Tasmanian case study, Political Geography 27, 160-175 (2008) 
8. F. Paul et al., Image Differences between Prospective, First-Time, and Repeat Visitors to the Lower Rio Grande Valley, Journal of Travel Research 30, 10, 10-16 (1991)

9. G. Martina et al., Destination Image-Toward a Conceptual Framework, Annals of Tourism Research 29, 1, 56-78 (2002)

10. O. Moufakkir, Destination Image Revised: the Dutch Market Perceptions of Morocco as a Tourism Destination in Tourism Development: Growth, Myths, and Inequalities ed. by P. Burns, Marina Novelli (CAB, UK, 2008)

11. Penghu County Government, Comprehensive Development Plan of Penghu County (Penghu County Government, Penghu County, 2004)

12. Penghu County Government, Electronic Bulletin System Files, (Penghu County Government, Penghu County, 2007-2013)

13. H. Hsueh-chi, The Sequel of Penghu County Book (1): Great Event Record (Penghu County Government, Penghu County, 2005)

14. Y. Chung-Lin etc., Wandering in Erkan (Penghu County Government, Penghu County, 2007)

15. S. Chao-Ying, T. Chi-Hsun, The trajectory of Comprehensive Community Building in Taiwan (The Council of Cultural Affairs, Taipei, 1999) 